\title{
Occurrence and remission of loss of sensitivity of inferior alveolar nerve in mandibular fractures
} Washington Geraldo Pellegrini Rocha-Junior ${ }^{1}$
https://orcid.org/0000-0003-3624-0105

Eduardo Pipino Pavan 1 https://orcid.org/0000-0001-7095-8343

João Gualberto Cerqueira Luz ${ }^{1,2}$ https://orcid.org/0000-0002-7686-7829

Hospital M. Dr. Arthur R. de Saboya, Serviço de Cirurgia e Traumatologia Bucomaxilofacial, São Paulo, São Paulo, Brasil.

Universidade de São Paulo - USP, Faculdade de Odontologia, Departamento de Cirurgia, Prótese e Traumatologia Maxilofaciais, São Paulo, São Paulo, Brasil.

Conflict of interests: Nonexistent

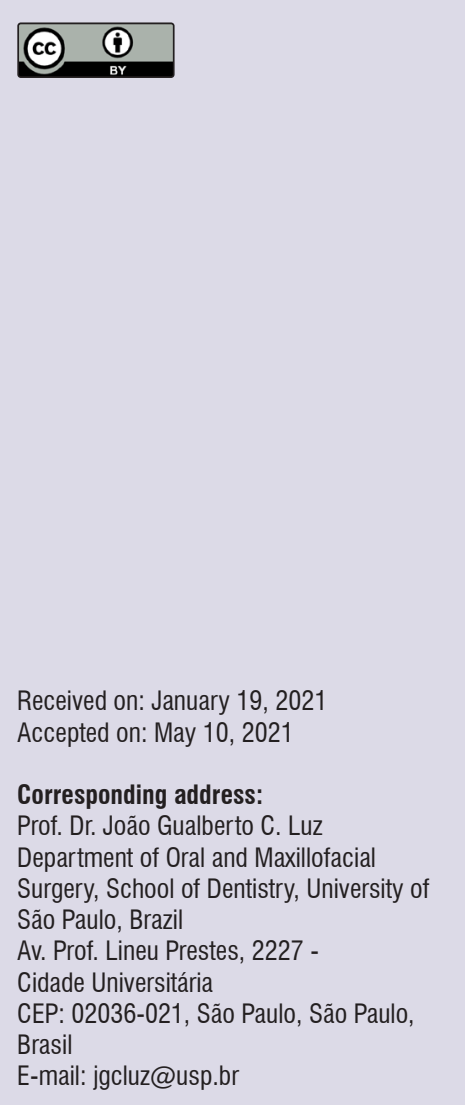

\section{ABSTRACT}

Purpose: to evaluate the occurrence of loss of sensitivity of the inferior alveolar nerve, and to monitor the remission of this change in patients with mandibular fractures subjected to surgical treatment.

Methods: patients with mandibular fractures, surgically treated within one year, were prospectively evaluated. Data regarding etiology, fracture location, type and displacement, and surgical access, were obtained. The tactile and thermal tests were applied at eighteen points in the mental region, within a period of six months. Statistical tests were applied to compare the categories of variables and the period of observation $(p \leq 0.050)$.

Results: during the study, 37 patients were included. There were 24 bilateral and 13 unilateral fractures. Sensory changes occurred in $56.8 \%$ of the patients in the preoperative period, in $83.8 \%$ of the patients, in the postoperative period, and $35.1 \%$ of the patients presented complete remission during the final period of the study.

Conclusion: sensory changes occurred in about half of the patients, due to the fracture, increasing greatly in the postoperative period, with complete remission in about one third of the cases. The fracture type, degree of displacement and surgical access type influenced the occurrence of sensory alterations.

Keywords: Paresthesia; Mandibular Fractures; Mandibular Injuries 


\section{INTRODUCTION}

Mandibular fractures represent one of the most frequent facial ones ${ }^{1-4}$. The ideal treatment for these fractures is internal fixation using plates and screws. Mandible fractures can result in damage to the lower alveolar nerve, with changes in sensorineural function. This can be caused by the primary injury, when the nerve is in the fracture line, or by secondary injuries, due to manipulation of the fracture ${ }^{5}$. Posttraumatic trigeminal nerve hypoesthesia is caused by indirect traumatic injury to the nerve bundle, compression due to edema, or direct nerve involvement within fracture stumps 6 .

Sensitivity is the conscious interpretation of environmental sensory stimuli. Losing it or having it changed temporarily in the lower alveolar nerve can cause important functional loss, such as difficulty in controlling saliva, feeding and speech ${ }^{7}$. Complaints about sensory changes can be in the form of pain, hypoaesthesia or anesthesia, as well as changes in thermal sensation and proprioception $^{8,9}$. The Seddon and Sunderland classifications are used in neural injuries ${ }^{10}$. These injuries are classified as neuropraxia, when there is no rupture of the nerve or its myelin sheath and when recovery occurs within 24 hours to 2 months; axonotmesis, when axons rupture but the epineural sheath remains intact and when recovery occurs in 2 to 4 months, but can reach up to 12 months; and neurotmesis, when partial or complete rupture occurs and recovery of sensitivity is unlikely ${ }^{10}$.

The incidence and long-term results of neurosensitive deficits of the lower alveolar nerve associated with mandible fractures are insufficiently documented in the literature ${ }^{11,12}$. An incidence of $5.7 \%$ to $58.5 \%$ of these neural injuries related to mandible fractures has been reported, increasing in the angle and body regions ${ }^{13,14}$. The incidence of lesions of the lower alveolar nerve in mandible fractures treated surgically varies from $0.4 \%$ to $91.3 \%$, with fractures in the angle and body regions ranging from $76.1 \%$ to $91.3 \% \%^{12,15,16}$.

The purpose of this study was to evaluate the occurrence of loss of sensation of the inferior alveolar nerve and to monitor the remission of these changes in patients with fractures of the mandible, subjected to surgical treatment.

\section{METHODS}

Patients diagnosed with mandibular fractures who underwent surgical treatment and were admitted to the
Oral and Maxillofacial Surgery Clinic between August 2016 and July 2018 were prospectively evaluated. All of the patients who participated in the study provided informed consent. This study received approval from the Human Research Ethics Committee of the School of Dentistry, University of São Paulo, Brazil (Protocol No. 78087817.0.0000.0086).

Patients with a diagnosis of mandibular fracture, aged 18 years or older, regardless of sex and race, who needed surgical treatment by fixation with plates and screws were included. Patients with a history of surgery or trauma in the mandible region, those with neurological disorders and those who were conservatively treated for mandibular fractures were excluded from the study. No specific treatment was performed for sensory alterations, only counseling for the patients to perform functional movements associated with the mandible and lips. Such functional movements were basically to perform circular movements with the hand over the lower lip under warm water, usually during the bath, and the mouth opening effortlessly. These exercises were monitored weekly but were not recorded.

Data were collected for each patient regarding age, sex, etiology, fracture location, type of fracture, degree of fracture dislocation and surgical access used. Computed tomography scans were used to determine the fracture characteristics of each patient.

The patients underwent tactile and thermal tests. The tactile test was performed with a $30 \times 08 \mathrm{~mm}$ needle, with the needle resting between the thumb and index finger of the professional sliding right and left over each study point for $4 \mathrm{~s}$. The thermal test was performed with a cold cotton swab for one second over each study point, obtained using dry ice $\left(-50^{\circ} \mathrm{C}\right.$ coolant spray solution, Endo-Ice, Maquira Dental Products, Maringá, PR, Brazil) over each study point for 4s.

Both tests were applied at eighteen points in the chin region, with nine points on each side. The present sensitivity changes were considered, comprising nine points per hemiface, and the number obtained represented the total of changes found in a given case. The points were distributed horizontally in each hemiface: three aligned points from the midline, just below the lower lip to the labial commissure, three aligned points from the midline of the chin-labial groove to the region below the labial commissure and three further aligned points departing from the pogonion to the region below the labial commissure near the base of the mandible (Fig. 1). The evaluations were performed before the surgical procedure - the day before surgery, immediately - when 
a
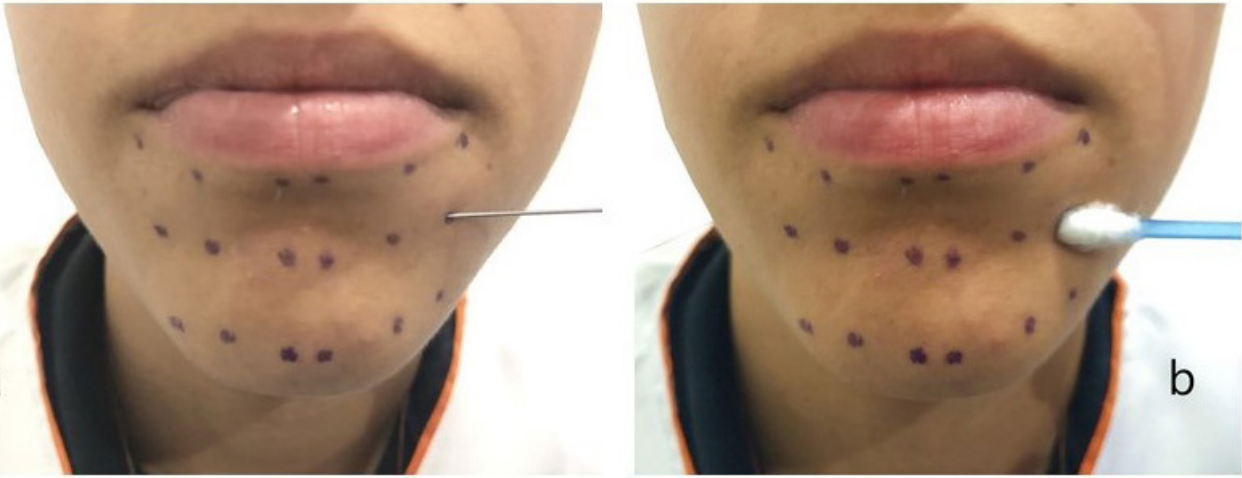

C

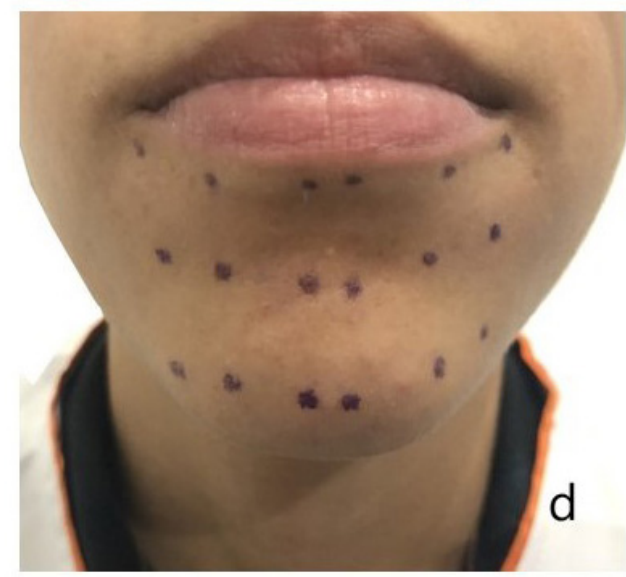

Figure 1. Method of carrying out tactile and thermal tests. a) Tactile test with a 30x7 needle. b) Thermal test with a cold cotton swab. c) Dry ice was used in the thermal test (cooling spray solution with temperature of $-50^{\circ} \mathrm{C}$, Endo-Ice, Maquira Dental Products, Maringá, PR, Brazil). d) Front view of mental region with 18 points for testing.

the patient had already been discharged from the postanesthetic recovery room, and one week, one, three and six months postoperatively.

The data obtained were submitted to statistical analysis in the statistical package IBM SPSS (Statistical Package for Social Sciences, IBM Software Group, Chicago, IL, USA), version 24.0. The Kruskal-Wallis test was used to compare, by observation period, for both sensitivity tests, the values of sensitive changes obtained, according to the etiology, fracture location, type of fracture, degree of displacement and type of surgical access. For all analyses, at level of $p \leq 0.050$ was considered significant.

\section{RESULTS}

During the evaluation period, 37 patients were included in this study according to the proposed criteria. The mean age of the patients was 29.3 years. There was a predominance of males with 30 patients (83.3\%). These patients had 24 bilateral fractures and 13 unilateral fractures, constituting a total of 61 sides that formed the analysis group.

The mean values of the sensory changes verified by the tactile and thermal sensitivity tests according to the observation period showed the presence of some preoperative sensory changes (tactile 2.31; thermal 2.28), followed by a large increase in the immediate postoperative period (tactile 4.61; thermal 4.80), which was followed by a progressive decrease from 7 days postoperatively (tactile 4.20; thermal 4.05), with a significant improvement at 3 months postoperatively (tactile 1.05; thermal 0.85) and almost no change in the 6-month postoperative period (tactile 0.69; thermal $0.46)$. Only four (10.8\%) patients had persistent sensory changes until the end of the study (Fig. 2). 


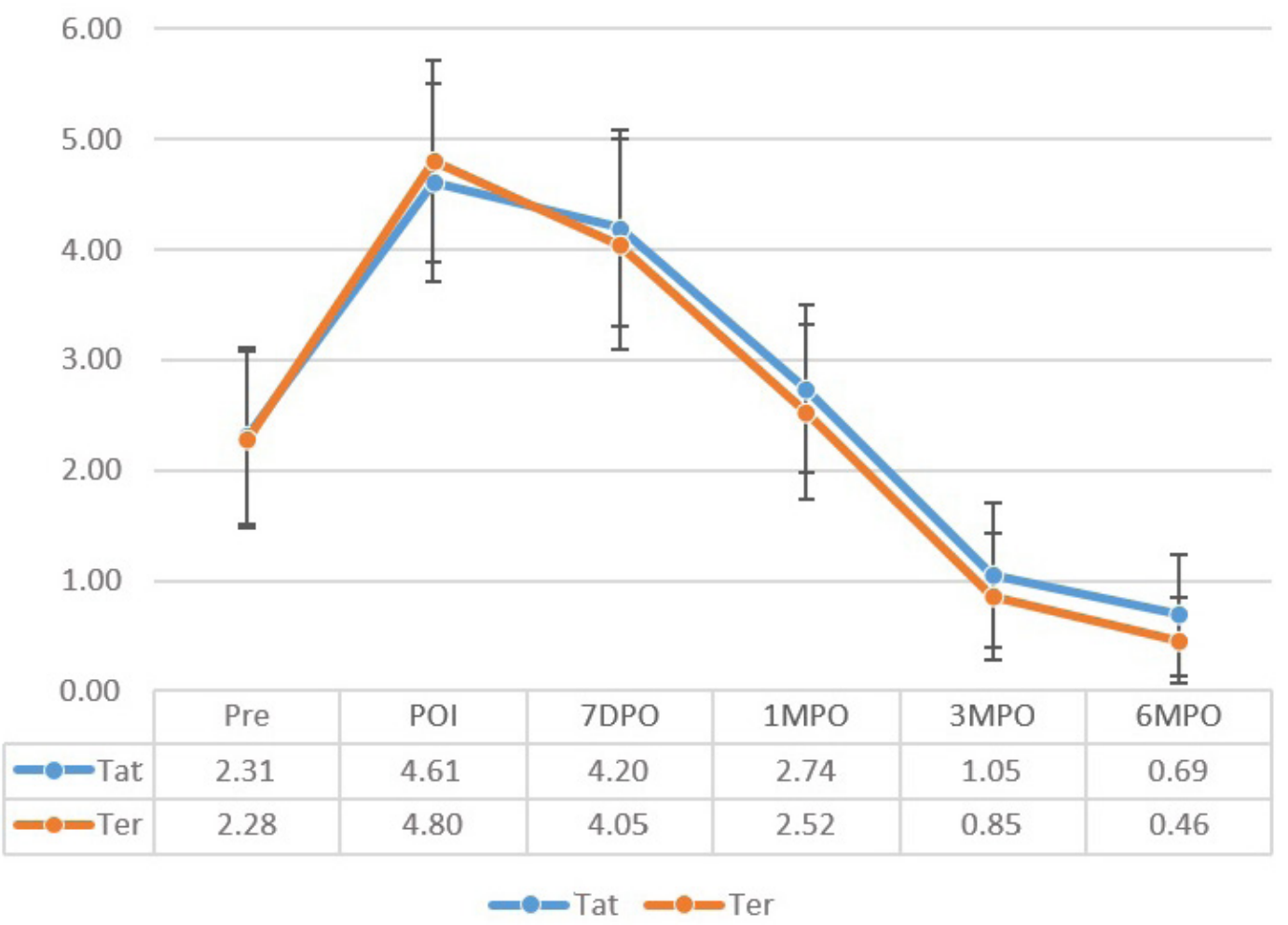

Figure 2. Mean values of the sensory changes verified by the tactile and thermal sensitivity tests according to the observation period. Pre: preoperative period; POI: immediate postoperative; 7DP0: 7 days postoperatively; 1MP0: 1 month postoperatively; 3MPO: 3 months postoperatively; 6MP0: 6 months postoperatively. Tat: tactile test; Ter: thermal test.

The mean values of the sensory changes verified by the tactile and thermal sensitivity tests according to the observation period and the etiology and significance of the Kruskal-Wallis test are shown in Table 1. In the comparison by observation period, for both tests, there was no statistically significant difference.
The mean values of the sensory changes verified by the tactile and thermal sensitivity tests according to the observation period as well as the fracture location and the significance of the Kruskal-Wallis test are shown in Table 2. In the comparison by observation period, for both tests, there was a statistically significant difference in the tactile test at 7 days postoperatively and in the thermal test at 1 month postoperatively. 
Table 1. Mean values of the sensory changes verified by the tactile and thermal sensitivity tests according to the observation period as well as the etiology and significance of the Kruskal-Wallis test

\begin{tabular}{|c|c|c|c|c|c|c|}
\hline \multirow{3}{*}{ Variable } & \multirow{3}{*}{ Etiology } & \multirow{3}{*}{$\mathbf{N}$} & \multicolumn{4}{|c|}{ Test } \\
\hline & & & \multicolumn{2}{|c|}{ Tactile } & \multicolumn{2}{|c|}{ Thermal } \\
\hline & & & Mean & S.D. & Mean & D.D. \\
\hline \multirow{7}{*}{ Preoperative } & Aggression & 18 & 3.44 & 3.50 & 3.67 & 3.50 \\
\hline & Automobile & 2 & 2.00 & 2.83 & 1.50 & 2.12 \\
\hline & Sports & 4 & 2.50 & 4.36 & 0.00 & 0.00 \\
\hline & Motorcycle & 21 & 1.57 & 2.60 & 2.10 & 3.06 \\
\hline & Falls & 16 & 2.00 & 3.35 & 1.63 & 3.05 \\
\hline & Total & 61 & 2.31 & 3.20 & 2.28 & 3.17 \\
\hline & $p$ value & & \multicolumn{2}{|c|}{0.555} & \multicolumn{2}{|c|}{0.104} \\
\hline \multirow{7}{*}{$\begin{array}{l}\text { Immediate } \\
\text { postoperative }\end{array}$} & Aggression & 17 & 5.00 & 3.97 & 4.71 & 3.98 \\
\hline & Automobile & 2 & 6.50 & 0.71 & 8.50 & 0.71 \\
\hline & Sports & 4 & 5.50 & 4.04 & 5.00 & 3.92 \\
\hline & Motorcycle & 21 & 4.19 & 3.61 & 4.62 & 3.81 \\
\hline & Falls & 16 & 4.25 & 3.53 & 4.56 & 3.44 \\
\hline & Total & 60 & 4.60 & 3.61 & 4.78 & 3.68 \\
\hline & $p$ value & & \multicolumn{2}{|c|}{0.784} & \multicolumn{2}{|c|}{0.660} \\
\hline \multirow{7}{*}{$\begin{array}{c}7 \text { days } \\
\text { postoperatively }\end{array}$} & Aggression & 17 & 4.53 & 3.78 & 4.59 & 4.03 \\
\hline & Automobile & 2 & 6.50 & 0.71 & 8.50 & 0.71 \\
\hline & Sports & 4 & 4.25 & 3.59 & 2.50 & 4.36 \\
\hline & Motorcycle & 21 & 3.76 & 3.86 & 4.00 & 4.00 \\
\hline & Falls & 15 & 4.00 & 3.40 & 3.47 & 3.42 \\
\hline & Total & 59 & 4.17 & 3.58 & 4.08 & 3.85 \\
\hline & $p$ value & & \multicolumn{2}{|c|}{0.883} & \multicolumn{2}{|c|}{0.398} \\
\hline \multirow{7}{*}{$\begin{array}{c}1 \text { month } \\
\text { postoperatively }\end{array}$} & Aggression & 14 & 3.29 & 3.75 & 2.36 & 3.10 \\
\hline & Automobile & 1 & 1.00 & 0.00 & 2.00 & 0.00 \\
\hline & Sports & 4 & 3.25 & 3.40 & 2.50 & 4.36 \\
\hline & Motorcycle & 21 & 2.76 & 3.42 & 3.24 & 3.74 \\
\hline & Falls & 14 & 2.50 & 2.59 & 2.43 & 2.90 \\
\hline & Total & 54 & 2.83 & 3.21 & 2.72 & 3.31 \\
\hline & $p$ value & & \multicolumn{2}{|c|}{0.985} & \multicolumn{2}{|c|}{0.991} \\
\hline \multirow{7}{*}{$\begin{array}{c}3 \text { months } \\
\text { postoperatively }\end{array}$} & Aggression & 8 & 2.25 & 4.17 & 1.88 & 3.56 \\
\hline & Automobile & 1 & 1.00 & 0.00 & 1.00 & 0.00 \\
\hline & Sports & 2 & 0.00 & 0.00 & 0.00 & 0.00 \\
\hline & Motorcycle & 17 & 1.94 & 3.23 & 1.59 & 2.96 \\
\hline & Falls & 10 & 1.20 & 2.70 & 0.90 & 2.23 \\
\hline & Total & 38 & 1.68 & 3.15 & 1.37 & 2.77 \\
\hline & $p$ value & & \multicolumn{2}{|c|}{0.681} & \multicolumn{2}{|c|}{0.675} \\
\hline \multirow{7}{*}{$\begin{array}{c}6 \text { months } \\
\text { postoperatively }\end{array}$} & Aggression & 6 & 3.00 & 4.65 & 2.33 & 3.83 \\
\hline & Automobile & 1 & 0.00 & 0.00 & 0.00 & 0.00 \\
\hline & Sports & 2 & 0.00 & 0.00 & 0.00 & 0.00 \\
\hline & Motorcycle & 13 & 1.08 & 2.63 & 0.62 & 1.26 \\
\hline & Falls & 10 & 1.00 & 2.31 & 0.60 & 1.58 \\
\hline & Total & 32 & 1.31 & 2.91 & 0.88 & 2.06 \\
\hline & $p$ value & & \multicolumn{2}{|c|}{0.796} & & \\
\hline
\end{tabular}


Table 2. Mean values of the sensory changes verified by the tactile and thermal sensitivity tests according to the observation period as well as the fracture location and significance of the Kruskal-Wallis test

\begin{tabular}{|c|c|c|c|c|c|c|}
\hline \multirow{3}{*}{ Variable } & \multirow{3}{*}{ Fracture location } & \multirow{3}{*}{$\mathbf{N}$} & \multicolumn{4}{|c|}{ Test } \\
\hline & & & \multicolumn{2}{|c|}{ Tactile } & \multicolumn{2}{|c|}{ Thermal } \\
\hline & & & Mean & S.D. & Mean & S.D. \\
\hline \multirow{7}{*}{ Preoperative } & Angle & 20 & 3.50 & 3.59 & 3.35 & 3.54 \\
\hline & Condyle & 12 & 1.83 & 3.33 & 0.67 & 1.50 \\
\hline & Body & 12 & 2.33 & 3.17 & 2.25 & 3.52 \\
\hline & Parasymphysis & 14 & 1.07 & 2.43 & 2.14 & 3.39 \\
\hline & Ramus & 3 & 2.00 & 1.73 & 2.33 & 0.58 \\
\hline & Total & 61 & 2.31 & 3.20 & 2.28 & 3.17 \\
\hline & $p$ value & & \multicolumn{2}{|c|}{0.236} & \multicolumn{2}{|c|}{0.234} \\
\hline \multirow{7}{*}{$\begin{array}{l}\text { Immediate } \\
\text { postoperative }\end{array}$} & Angle & 19 & 4.47 & 3.32 & 4.89 & 3.49 \\
\hline & Condyle & 12 & 2.25 & 3.44 & 2.67 & 3.70 \\
\hline & Body & 12 & 6.00 & 3.36 & 5.83 & 3.56 \\
\hline & Parasymphysis & 14 & 5.36 & 3.88 & 5.57 & 3.72 \\
\hline & Ramus & 3 & 5.67 & 3.06 & 4.67 & 4.04 \\
\hline & Total & 60 & 4.60 & 3.61 & 4.78 & 3.68 \\
\hline & $p$ value & & \multicolumn{2}{|c|}{0.102} & \multicolumn{2}{|c|}{0.252} \\
\hline \multirow{7}{*}{$\begin{array}{c}7 \text { days } \\
\text { postoperatively }\end{array}$} & Angle & 18 & 4.33 & 3.46 & 4.22 & 3.95 \\
\hline & Condyle & 12 & 1.75 & 2.45 & 1.08 & 1.73 \\
\hline & Body & 12 & 5.83 & 3.54 & 5.50 & 3.85 \\
\hline & Parasymphysis & 14 & 4.79 & 3.93 & 5.36 & 3.92 \\
\hline & Ramus & 3 & 3.33 & 3.51 & 3.67 & 4.73 \\
\hline & Total & 59 & 4.17 & 3.58 & 4.08 & 3.85 \\
\hline & $p$ value & & \multicolumn{2}{|c|}{0.044 * } & \multicolumn{2}{|c|}{0.053} \\
\hline \multirow{7}{*}{$\begin{array}{c}1 \text { month } \\
\text { postoperatively }\end{array}$} & Angle & 16 & 2.88 & 3.42 & 2.31 & 3.20 \\
\hline & Condyle & 12 & 1.42 & 1.88 & 0.58 & 1.17 \\
\hline & Body & 10 & 4.20 & 3.52 & 4.70 & 3.37 \\
\hline & Parasymphysis & 14 & 3.43 & 3.48 & 4.00 & 3.68 \\
\hline & Ramus & 2 & 0.00 & 0.00 & 0.00 & 0.00 \\
\hline & Total & 54 & 2.88 & 3.42 & 2.72 & 3.31 \\
\hline & $p$ value & & \multicolumn{2}{|c|}{0.166} & \multicolumn{2}{|c|}{$0.018^{*}$} \\
\hline \multirow{7}{*}{$\begin{array}{c}3 \text { months } \\
\text { postoperatively }\end{array}$} & Angle & 12 & 1.75 & 3.36 & 1.68 & 3.15 \\
\hline & Condyle & 7 & 0.00 & 0.00 & 1.50 & 3.12 \\
\hline & Body & 6 & 3.00 & 4.29 & 0.00 & 0.00 \\
\hline & Parasymphysis & 11 & 2.27 & 3.32 & 2.33 & 3.27 \\
\hline & Ramus & 2 & 0.00 & 0.00 & 1.82 & 3.13 \\
\hline & Total & 38 & 1.68 & 3.15 & 0.00 & 0.00 \\
\hline & $p$ value & & \multicolumn{2}{|c|}{0.270} & \multicolumn{2}{|c|}{0.297} \\
\hline \multirow{7}{*}{$\begin{array}{c}6 \text { months } \\
\text { postoperatively }\end{array}$} & Angle & 12 & 1.73 & 3.26 & 1.36 & 2.94 \\
\hline & Condyle & 7 & 0.00 & 0.00 & 0.29 & 0.76 \\
\hline & Body & 6 & 2.60 & 3.98 & 1.80 & 2.49 \\
\hline & Parasymphysis & 11 & 1.25 & 3.15 & 0.25 & 0.71 \\
\hline & Ramus & 2 & 0.00 & 0.00 & 0.00 & 0.00 \\
\hline & Total & 32 & 1.31 & 2.91 & 0.88 & 2.06 \\
\hline & $p$ value & & \multicolumn{2}{|c|}{0.497} & & \\
\hline
\end{tabular}

${ }^{*}$ Significant $(p \leq 0.050)$. 
The mean values of the sensory changes verified by the tactile and thermal sensitivity tests according to the observation period as well as the type of fracture and the significance of the Kruskal-Wallis test can be observed in Table 3. In the comparison by observation period, for both tests, there was a statistically significant difference in the thermal test at 3 months postoperatively.

Table 3. Mean values of the sensory changes verified by the tactile and thermal sensitivity tests according to the observation period as well as the type of fracture and significance of the Kruskal-Wallis test

\begin{tabular}{|c|c|c|c|c|c|c|}
\hline \multirow{3}{*}{ Variable } & \multirow{3}{*}{ Fracture type } & \multirow{3}{*}{ N } & \multicolumn{4}{|c|}{ Test } \\
\hline & & & \multicolumn{2}{|c|}{ Tactile } & \multicolumn{2}{|c|}{ Thermal } \\
\hline & & & Mean & S.D. & Mean & S.D. \\
\hline \multirow{5}{*}{ Preoperative } & Comminuted & 2 & 4.50 & $6 . .36$ & 4.50 & 6.36 \\
\hline & Multiple & 5 & 2.80 & 3.70 & 2.80 & 3.70 \\
\hline & Simple & 54 & 2.19 & 3.09 & 2.15 & 3.06 \\
\hline & Total & 61 & 2.31 & 3.20 & 2.28 & 3.17 \\
\hline & $p$ value & & \multicolumn{2}{|c|}{0.715} & \multicolumn{2}{|c|}{0.592} \\
\hline \multirow{5}{*}{$\begin{array}{l}\text { Immediate } \\
\text { postoperative }\end{array}$} & Comminuted & 2 & 8.00 & 1.41 & 8.50 & 0.71 \\
\hline & Multiple & 5 & 5.60 & 3.29 & 5.20 & 4.38 \\
\hline & Simple & 53 & 4.38 & 3.65 & 4.60 & 3.64 \\
\hline & Total & 60 & 4.60 & 3.61 & 4.78 & 3.68 \\
\hline & $p$ value & & \multicolumn{2}{|c|}{0.290} & \multicolumn{2}{|c|}{0.257} \\
\hline \multirow{5}{*}{$\begin{array}{c}7 \text { days } \\
\text { postoperativel }\end{array}$} & Comminuted & 2 & 8.00 & 1.41 & 8.50 & 0.71 \\
\hline & Multiple & 5 & 4.40 & 3.85 & 5.00 & 4.64 \\
\hline & Simple & 52 & 4.00 & 3.58 & 3.83 & 3.78 \\
\hline & Total & 59 & 4.17 & 3.58 & 4.08 & 3.85 \\
\hline & $p$ value & & \multicolumn{2}{|c|}{0.304} & \multicolumn{2}{|c|}{0.201} \\
\hline \multirow{5}{*}{$\begin{array}{c}1 \text { month } \\
\text { postoperatively }\end{array}$} & Comminuted & 2 & 6.00 & 1.41 & 8.50 & 0.71 \\
\hline & Multiple & 4 & 3.00 & 4.24 & 3.75 & 4.50 \\
\hline & Simple & 48 & 2.69 & 3.16 & 2.40 & 3.07 \\
\hline & Total & 54 & 2.83 & 3.21 & 2.72 & 3.31 \\
\hline & $p$ value & & \multicolumn{2}{|c|}{0.365} & \multicolumn{2}{|c|}{0.072} \\
\hline \multirow{5}{*}{$\begin{array}{c}3 \text { months } \\
\text { postoperatively }\end{array}$} & Comminuted & 2 & 5.50 & 0.71 & 7.50 & 2.12 \\
\hline & Multiple & 4 & 2.25 & 4.50 & 2.25 & 4.50 \\
\hline & Simple & 32 & 1.38 & 2.96 & 0.88 & 2.06 \\
\hline & Total & 38 & 1.68 & 3.15 & 1.37 & 2.77 \\
\hline & $p$ value & & \multicolumn{2}{|c|}{0.093} & \multicolumn{2}{|c|}{0.024 * } \\
\hline \multirow{5}{*}{$\begin{array}{c}6 \text { months } \\
\text { postoperatively }\end{array}$} & Comminuted & 1 & 1.00 & 0.00 & 2.00 & 0.00 \\
\hline & Multiple & 4 & 2.25 & 4.50 & 2.25 & 4.50 \\
\hline & Simple & 27 & 1.19 & 2.76 & 0.63 & 1.52 \\
\hline & Total & 32 & 1.31 & 2.91 & 0.88 & 2.06 \\
\hline & $p$ value & & \multicolumn{2}{|c|}{0.334} & \multicolumn{2}{|c|}{0.226} \\
\hline
\end{tabular}

${ }^{\star}$ Significant $(p \leq 0.050)$. 
The mean values of the sensory changes verified by the tactile and thermal sensitivity tests according to the observation period as well as the degree of displacement and the significance of the KruskalWallis test are shown in Table 4. In the comparison by observation period, for both tests, there was a statistically significant difference in both tests in the preoperative period and in the thermal test at 1 month postoperatively.

Table 4. Mean values of the sensory changes verified by the tactile and thermal sensitivity tests according to the observation period as well as the degree of displacement and significance of the Kruskal-Wallis test

\begin{tabular}{|c|c|c|c|c|c|c|}
\hline \multirow{3}{*}{ Variable } & \multirow{3}{*}{$\begin{array}{c}\text { Degree of } \\
\text { displacement }\end{array}$} & \multirow{3}{*}{$\mathbf{N}$} & \multicolumn{4}{|c|}{ Test } \\
\hline & & & \multicolumn{2}{|c|}{ Tactile } & \multicolumn{2}{|c|}{ Thermal } \\
\hline & & & Mean & S.D. & Mean & S.D. \\
\hline \multirow{5}{*}{ Preoperative } & No displacement & 11 & 0.73 & 2.41 & 0.55 & 1.81 \\
\hline & Less than $5 \mathrm{~mm}$ & 31 & 2.16 & 2.99 & 2.42 & 3.35 \\
\hline & Greater than $5 \mathrm{~mm}$ & 19 & 3.47 & 3.60 & 3.05 & 3.24 \\
\hline & Total & 61 & 2.31 & 3.20 & 2.28 & 3.17 \\
\hline & $p$ value & & \multicolumn{2}{|c|}{0.715} & \multicolumn{2}{|c|}{0.592} \\
\hline \multirow{5}{*}{$\begin{array}{c}\text { Immediate } \\
\text { postoperative }\end{array}$} & No displacement & 11 & 3.27 & 4.03 & 3.18 & 4.26 \\
\hline & Less than $5 \mathrm{~mm}$ & 31 & 5.29 & 3.45 & 5.39 & 3.33 \\
\hline & Greater than $5 \mathrm{~mm}$ & 18 & 4.22 & 3.54 & 4.72 & 3.79 \\
\hline & Total & 60 & 4.60 & 3.61 & 4.78 & 3.68 \\
\hline & $p$ value & & \multicolumn{2}{|c|}{0.249} & \multicolumn{2}{|c|}{0.353} \\
\hline \multirow{5}{*}{$\begin{array}{c}7 \text { days } \\
\text { postoperatively }\end{array}$} & No displacement & 11 & 3.09 & 4.13 & 3.09 & 4.32 \\
\hline & Less than $5 \mathrm{~mm}$ & 30 & 4.90 & 3.46 & 4.93 & 3.79 \\
\hline & Greater than $5 \mathrm{~mm}$ & 18 & 3.61 & 3.36 & 3.28 & 3.55 \\
\hline & Total & 59 & 4.17 & 3.58 & 4.08 & 3.85 \\
\hline & $p$ value & & \multicolumn{2}{|c|}{0.246} & \multicolumn{2}{|c|}{0.211} \\
\hline \multirow{5}{*}{$\begin{array}{c}1 \text { month } \\
\text { postoperatively }\end{array}$} & No displacement & 10 & 1.70 & 3.34 & 1.10 & 2.03 \\
\hline & Less than $5 \mathrm{~mm}$ & 29 & 3.31 & 3.23 & 3.72 & 3.58 \\
\hline & Greater than $5 \mathrm{~mm}$ & 15 & 2.67 & 3.11 & 1.87 & 2.92 \\
\hline & Total & 54 & 2.83 & 3.21 & 2.72 & 3.31 \\
\hline & $p$ value & & \multicolumn{2}{|c|}{0.257} & \multicolumn{2}{|c|}{0.048} \\
\hline \multirow{5}{*}{$\begin{array}{c}3 \text { months } \\
\text { postoperatively }\end{array}$} & No displacement & 8 & 0.13 & 0.35 & 0.13 & 0.35 \\
\hline & Less than $5 \mathrm{~mm}$ & 20 & 2.15 & 3.54 & 1.75 & 3.02 \\
\hline & Greater than $5 \mathrm{~mm}$ & 10 & 2.00 & 3.37 & 1.60 & 3.20 \\
\hline & Total & 38 & 1.68 & 3.15 & 1.37 & 2.77 \\
\hline & $p$ value & & \multicolumn{2}{|c|}{0.499} & \multicolumn{2}{|c|}{0.512} \\
\hline \multirow{5}{*}{$\begin{array}{c}6 \text { months } \\
\text { postoperatively }\end{array}$} & No displacement & 7 & 0.00 & 0.00 & 0.00 & 0.00 \\
\hline & Less than $5 \mathrm{~mm}$ & 17 & 1.94 & 3.29 & 1.24 & 2.51 \\
\hline & Greater than $5 \mathrm{~mm}$ & 8 & 1.13 & 3.18 & 0.88 & 1.81 \\
\hline & Total & 32 & 1.31 & 2.91 & 0.88 & 2.06 \\
\hline & $p$ value & & \multicolumn{2}{|c|}{0.161} & \multicolumn{2}{|c|}{0.295} \\
\hline
\end{tabular}

*Significant $(p \leq 0.050)$. 
The mean values of the sensory changes verified by the tactile and thermal sensitivity tests according to the observation period as well as the type of surgical access and the significance of the Kruskal-Wallis test can be observed in Table 5. In the comparison by observation period, for both tests, there was a statistically significant difference in both tests in the immediate period, at 7 days and 1 month postoperatively.

Table 5. Mean values of the sensory changes verified by the tactile and thermal sensitivity tests according to the observation period and the type of surgical access as well as significance of the Kruskal-Wallis test

\begin{tabular}{|c|c|c|c|c|c|c|}
\hline \multirow{3}{*}{ Variable } & \multirow{3}{*}{ Surgical access } & \multirow{3}{*}{$\mathbf{N}$} & \multicolumn{4}{|c|}{ Test } \\
\hline & & & \multicolumn{2}{|c|}{ Tactile } & \multicolumn{2}{|c|}{ Thermal } \\
\hline & & & Mean & S.D. & Mean & S.D. \\
\hline \multirow{4}{*}{ Preoperative } & Intra-oral & 31 & 2.29 & 3.31 & 2.52 & 3.41 \\
\hline & Extra-oral & 30 & 2.33 & 3.13 & 2.03 & 2.94 \\
\hline & Total & 61 & 2.31 & 3.20 & 2.28 & 3.17 \\
\hline & $p$ value & & \multicolumn{2}{|c|}{0.969} & \multicolumn{2}{|c|}{0.715} \\
\hline \multirow{4}{*}{$\begin{array}{l}\text { Immediate } \\
\text { postoperative }\end{array}$} & Intra-oral & 31 & 5.45 & 3.49 & 5.74 & 3.42 \\
\hline & Extra-oral & 29 & 3.69 & 3.57 & 3.76 & 3.73 \\
\hline & Total & 60 & 4.60 & 3.61 & 4.78 & 3.68 \\
\hline & $p$ value & & \multicolumn{2}{|c|}{0.046 * } & \multicolumn{2}{|c|}{0.029 * } \\
\hline \multirow{4}{*}{$\begin{array}{c}7 \text { days } \\
\text { postoperatively }\end{array}$} & Intra-oral & 30 & 5.23 & 3.53 & 5.47 & 3.76 \\
\hline & Extra-oral & 29 & 3.07 & 3.35 & 2.66 & 3.46 \\
\hline & Total & 59 & 4.17 & 3.58 & 4.08 & 3.85 \\
\hline & $p$ value & & \multicolumn{2}{|c|}{0.012 * } & \multicolumn{2}{|c|}{0.004 * } \\
\hline \multirow{4}{*}{$\begin{array}{c}1 \text { month } \\
\text { postoperatively }\end{array}$} & Intra-oral & 27 & 3.85 & 3.36 & 3.96 & 3.33 \\
\hline & Extra-oral & 27 & 1.81 & 2.76 & 1.48 & 2.83 \\
\hline & Total & 54 & 2.83 & 3.21 & 2.72 & 3.31 \\
\hline & $p$ value & & \multicolumn{2}{|c|}{0.017 * } & \multicolumn{2}{|c|}{0.002 * } \\
\hline \multirow{4}{*}{$\begin{array}{c}3 \text { months } \\
\text { postoperatively }\end{array}$} & Intra-oral & 17 & 2.12 & 3.46 & 1.41 & 2.72 \\
\hline & Extra-oral & 21 & 1.33 & 2.90 & 1.33 & 2.87 \\
\hline & Total & 38 & 1.68 & 3.15 & 1.37 & 2.77 \\
\hline & $p$ value & & \multicolumn{2}{|c|}{0.306} & \multicolumn{2}{|c|}{0.383} \\
\hline \multirow{4}{*}{$\begin{array}{c}6 \text { months } \\
\text { postoperatively }\end{array}$} & Intra-oral & 15 & 1.67 & 3.22 & 0.93 & 2.46 \\
\hline & Extra-oral & 17 & 1.00 & 2.67 & 0.82 & 1.70 \\
\hline & Total & 32 & 1.31 & 2.91 & 0.88 & 2.06 \\
\hline & $p$ value & & \multicolumn{2}{|c|}{0.514} & \multicolumn{2}{|c|}{0.814} \\
\hline
\end{tabular}

*Significant $(p \leq 0.050)$

\section{DISCUSSION}

In this study, there were sensory changes, quantified by the number of points with no tactile or thermal sensitivity, in the preoperative period, the patients presented with an increase in these changes in the immediate postoperative period, with total remission of these changes during the study period. There was a progressive remission of the changes within 1 month postoperatively. Only four patients showed persistence of sensory changes at the end of the study. In our study, tactical and thermal tests were used and both were chosen because they are of the objective type.
In addition, the response to thermal test is considered excellent ${ }^{17}$. These tests were applied at eighteen points in the chin region. Such points covered the areas innervated by labial branch of inferior alveolar nerve and the mental branch of inferior alveolar nerve ${ }^{17}$.

It was found that the etiology did not influence the occurrence of sensory changes. In the comparison by observation period and etiology, for the tactile and thermal tests, there was no statistically significant difference. In the literature, the etiology factor has not been described as significant ${ }^{18}$. Nevertheless, a study showed that assaults seem to be the most important 
etiological factor that is responsible for inferior alveolar nerve lesions ${ }^{14}$.

An influence of the location of the fracture on the occurrence of sensory changes was found. There was a significant difference in the comparison by observation period and location in the tactile test at 7 days, with the location in the condyle showing lower values. There was also a significant difference in the thermal test at 1 month, with the location on the ramus showing lower values. There was an improvement after 7 days postoperatively, with better values in fractures located outside or near the entrance of the mandibular foramen. The angle showed higher values of changes since the preoperative period, increasing in the immediate postoperative period. The body maintained the highest values until the end of the study. Recovery patterns of posttraumatic trigeminal dysfunction are related to the site of fracture ${ }^{6}$. A significant association between inferior alveolar nerve sensory disturbances and angle fractures has been described ${ }^{14}$. Another study showed a higher frequency of sensory changes in angle fractures and worse recovery in body fractures ${ }^{18}$.

There was an influence of the type of fracture on the occurrence of sensory changes. There was a significant difference in the comparison by observation period and the type of fracture in the thermal test at 3 months postoperatively. The simple fracture line showed lower values, and probably, the type of nerve injury would have been less intense. Recovery patterns of posttraumatic trigeminal dysfunction are related to the type of fracture ${ }^{6}$. The passage of nerve bundle within a bony canal can be considered a risk factor for the onset of longer posttraumatic dysfunction, as small fragments can occur inside the canal with a consequent longer region of compression of nerve fibers ${ }^{6}$. It can be said that the type of nerve injury varies greatly because of the fracture type ${ }^{8}$. Studies showed that the change in sensitivity may be due to nerve rupture by sharp bone fragments ${ }^{18}$, or in comminuted fractures ${ }^{19}$.

An influence of the degree of fracture displacement was observed in the occurrence of sensory changes. There was a significant difference in the comparison by observation period and the degree of fracture displacement, in both tests in the preoperative period and in the thermal test at 1 month postoperatively, with fractures without displacement showing lower values. This better result was probably due to the preservation of the alveolar nerve within the mandibular canal. The type of nerve injury varies greatly because of the fracture displacement ${ }^{8}$. Fractures with a large displacement have been associated with a higher incidence of nerve injury ${ }^{19}$. It has been demonstrated that displacements greater than $5 \mathrm{~mm}$ presented long sensory recovery 5,9 . Additionally, excessive mobility at a fracture site, even if minimally displaced, might contribute to additional nerve injury and a subsequent poor prognosis for recovery ${ }^{20}$. Prolonged neurosensory disturbance is greatly related to the degree of manipulation of the inferior alveolar nerve ${ }^{17}$.

An influence of the type of surgical access on the occurrence of sensitive changes was found. There was a significant difference by observation period and type of surgical access in both tests in the immediate postoperative period. There was also a significant difference in both tests 7 days and 1 month after surgery. Major changes were found in intraoral access. The limited visualization of the operative field offered by intraoral access can be a possibility of a greater occurrence of sensitive injury. Nerve damage can occur during dissection and factors such as mucoperiosteal detachment and an incision close to the mental foramen can cause sensory changes ${ }^{18,20}$. Regardless of the characteristics of the fracture, there is a risk of neural injury during treatment, even in the absence of initial changes due to the fracture. It is therefore relevant to warn the patient of the risk ${ }^{9}$.

One clinical limitation of this study could be that no specific treatment was performed for sensory changes, such as medication, laser or orofacial motricity, only counseling for the patient to perform functional movements associated with the mandible and lips. A possible limitation of this study could be the sample size. Although 37 cases of mandibular fractures were detected, the sample size was not calculated.

\section{CONCLUSION}

Based on the data collected in this study, it was concluded that the occurrence of loss of sensation of the inferior alveolar nerve was in about half of the patients, due to the mandibular fracture, increasing greatly in the postoperative period, with complete remission of these changes in about one third of the cases. The fracture type, degree of displacement and surgical access type influenced the occurrence of sensory alterations. 


\section{REFERENCES}

1. Erdmann D, Follmar KE, Debruijn M, Bruno AD, Jung $\mathrm{SH}$, Edelman $\mathrm{D}$ et al. A retrospective analysis of facial fracture etiologies. Ann Plast Surg. 2008;60(4):398-403.

2. Zhi Li, Zu-Bing L. Clinical characteristics and treatment of multiple site comminuted mandible fractures. J Craniomaxillofac Surg. 2011;39(4):296-9.

3. Mayrink G, Moreira RWF, Araujo MM. Prospective study of postoperative sensory disturbances after surgical treatment of mandibular fractures. Oral Maxillofac Surg. 2013;17(1):27-31.

4. Zhou HH, Liu Q, Cheng G, Li ZB. Aetiology, pattern and treatment of mandibular condylar fractures in 549 patients: a 22-year retrospective study. J Craniomaxillofac Surg. 2013;41(1):34-41.

5. Halpern LR, Kaban LB, DodsonTB, Perioperative neurosensory changes associated with treatment of mandibular fractures. J Oral Maxillofac Surg. 2004;62(5):576-81.

6. Renzi G, Carboni A, Perugini M, Giovannetti F, Becelli R. Posttraumatic trigeminal nerve impairment: a prospective analysis of recovery patterns in a series of 103 consecutive facial fractures. J Oral Maxillofac Surg. 2004;62(11):1341-6.

7. Graziani AF, Garcia CFS, Berretin-Felix G, Genaro KF. Orthognathic surgery effect of orofacial sensitivity in individuals with cleft lip and palate. Rev. CEFAC. 2016;18(3):581-7.

8. Poort LJ, van Neck JW, van der Wal KG. Sensory testing of inferior alveolar nerve injuries: a review of methods used in prospective studies. J Oral Maxillofac Surg. 2009;67(2):292-300.

9. Song Q, Li S, Patil PM. Inferior alveolar and mental nerve injuries associated with open reduction and internal fixation of mandibular fractures: a seven year retrospective study. J.Craniomaxillofac Surg. 2014;42(7):1378-81.

10. Robinson PP. Observations on the recovery of sensation following inferior alveolar nerve injuries. Br J Oral Maxillofac Surg. 1988;26(3):177-89.

11. Marchena JM, Padwa BL, Kaban LB. Sensory abnormalities associated with mandibular fractures: incidence and natural history. J Oral Maxillofac Surg. 1998;56(7):822-5.
12. Yadav S, Mittal HC, Malik S, Dhupar V, Sachdeva A, Malhotra $V$ et al. Post-traumatic and postoperative neurosensory deficits of the inferior alveolar nerve in mandibular fracture: a prospective study. J Korean Assoc Oral Maxillofac Surg. 2016;42(5):259-64.

13. Thurmüller $P$, Dodson TB, Kaban LB. Nerve injuries associated with facial trauma: natural history, management, and outcomes of repair. Oral Maxillofac Surg Clin North Am. 2001;13(2):283-94.

14. Boffano P, Roccia F, Gallesio C, Karagozoglu K. Inferior alveolar nerve injuries associated with mandibular fractures at risk: A two-center retrospective study. Craniomaxillofac Trauma Reconstr. 2014;7(4):280-3.

15. Schultze-Mosgau S, Erbe M, Rudolph D, Ott R, Neukam FW. Prospective study on post-traumatic and postoperative sensory disturbances of the inferior alveolar nerve and infraorbital nerve in mandibular and midfacial fractures. $J$ Craniomaxillofac Surg. 1999;27(2):86-93.

16. Tay ABG, Lai JB, Lye KW, Wong WY, Nadkarni NV, $\mathrm{Li} W$ et al. Inferior alvealar nerve injury in traumainduced mandible fractures. J Oral Maxillofac Surg. 2015;73(7):1328-40.

17. Antony PG, Sebastian A, Varghese KG, Sobhana CR, Mohan S, Soumithran CS et al. Neurosensory evaluation of inferior alveolar nerve after bilateral sagittal split ramus osteotomy of mandible. $\mathrm{J}$ Oral Biol Craniofac Res. 2017;7(2):81-8.

18. Schenkel JS, Jacobsen C, Rostetter C, Grätz KW, Rücker M, Gander T. Inferior alveolar nerve function after open reduction and internal fixation of mandibular fractures. J Craniomaxillofac Surg. 2016;44(6):743-8.

19. Bede SYH, Ismael WK, Al-Assaf DA, Omer SS. Inferior alveolar nerve injuries associated with mandibular fractures. J Craniofac Surg. 2012;23(6):1776-8.

20. Scott RA, Teo N, Perry M. Displacement of mandibular fractures: Is there a correlation with sensory loss and recovery? Int J Oral Maxillofac Surg. 2014;43(5):555-8. 